\title{
XU THẾ CẢI CÁCH CHƯƠNG TRÌNH ĐÀO TẠO TẠI CÁC NƯỚC TRÊN THẾ GIỚI - THÁCH THỬC VÀ CƠ HộI NGUỒN NHÂN LỰC LĨNH VỰC TRÁI ĐẤT- MỎ - MỐI TRƯỜNG
}

\author{
Đào Viết Đoàn ${ }^{1}$, Đỗ Ngọc Anh ${ }^{1}$, Đặng Trung Thành', \\ Trần Tuấn Minh ${ }^{1}$, Nguyễn Văn Mạnh ${ }^{1}$
}

Tóm tắt: Bài viết trình bày khái quát chung về toàn cầu hóa giáo duc, sự cần thiết cải cách chưong trình đào tạo và giới thiệu về xu thế cái cách chương trình đào tạo tại các nước trên thế giới. Trên co sở phân tích những thách thức, khó khăn, co hội của nguồn nhân lục lĩnh vục khoa học Trái đất - Mỏ - Môi truờng trong bối cảnh toàn cầu hóa và xu thế cải cách chuoong trình đào tạo trên thế giới. Nhóm tác giả đã đề xuất một số nhóm giải pháp cần thiết để nâng cao chất lượng đào tạo nguồn nhân lực đáp úng yêu cầu trong lĩnh vục khoa học Trái đất - Mỏ - Môi truò̀ng, bao gồm: Nâng cao trình độ đội ngũ đào tạo nghiên cưu khoa hoc; Cải cách chuơng trình đào tạo; Đầu tư co sở vật chất trang thiết bị phuc vu đào tạo và nghiên cưu khoa hoc; Tăng cuờng kết hợp với các co sở nghiên cưu, doanh nghiệp; Chủ động hội nhập quốc tế; Giáo dục hướng nghiệp và tổ chức huớng nghiẹp cho nguòi họ.

Từ khóa: Cải cách chưong trình đào tạo, nâng cao nguồn nhân lực, khoa hoc Trái đất - Mỏ Môi truòng.

Ban Biên tập nhận bài: 11/12/2019 Ngày phản biện xong: 12/12/2019 ～Ngày đăng: 20/12/2019

\section{Cải cách giáo dục trong bối cảnh toàn cầu hóa}

Toàn cầu hóa giáo dục vừa là biểu hiện của toàn cầu hóa kinh tế vừa là sản phẩm của toàn cầu hóa kinh tế. Ngày nay với xu thế toàn cầu hóa kinh tế đã đòi hỏi nguồn nhân lực cũng mang tính toàn cầu hóa từ đó dẫn đến sự lưu động với số lượng lớn các sinh viên, nhà nghiên cứu khoa học công nghệ trên toàn thế giới, đặc biệt là sự lưu động của học sinh sinh viên, nhà khoa học từ các nước đang phát triển đến các nước phát triển.

Toàn cầu hóa đang diễn ra một cách nhanh chóng, mạnh mẽ, gây tác động sâu sắc đến mọi lĩnh vực của đời sống xã hội. Trong bối cảnh toàn cầu hóa, đa số các quốc gia, các ngành đào tạo truyền thống đang tỏ ra lúng túng, mơ hồ trong việc xử lý và định hình một chiến lược giáo dục tổng thể đáp ứng những thay đổi nhanh chóng của thời đại, giáo dục đại học sẽ thay đổi sâu rộng từ môi trường giáo dục, vai trò của người dạy, người học đến phương pháp dạy học. Hiện nay, không chỉ Việt Nam mà nhiều quốc gia trên thế giới đang phải đối mặt với thách thức lớn về thiếu hụt lao động trình độ cao, có chuyên môn, kỹ năng. Do đó cần đổi mới giáo dục đại học, đáp ứng yêu cầu của thị trường lao động, nâng cao nhận thức, đổi mới tư duy về phát triển giáo dục đại học, đổi mới chương trình và phương thức đào tạo, áp dụng công nghệ thông tin vào trong quá trình giảng dạy, đổi mới mô hình liên kết giữa trường đại học và doanh nghiệp, nâng cao chất lượng đội ngũ đào tạo và cán bộ quản lý.

${ }^{1}$ Trường Đại hoc Mỏ - Địa chất

Email:daovietdoan@gmail.com 
Trong bối cảnh toàn cầu hóa để tránh khỏi tụt hậu, thích ứng kịp thời với sự thay đổi từng ngày, từng giờ của sản xuất, của tiến bộ khoa học kỹ thuật cũng như trong đời sống thì mỗi cá nhân và cộng đồng không thể không trang bị những kiến thức, kỹ năng mới, điều chỉnh ứng xử phù hợp với những đổi mới đang liên tục xuất hiện. Vì vậy các quốc gia trên thế giới đều phải cải cách giáo dục, thay đổi chương trình đào tạo cho phù hợp với thực tế toàn cầu hóa.

Trong bối cảnh toàn cầu hóa ngành khoa học Trái đất - Mỏ - Môi trường cũng đang đứng trước những vấn đề về đào tạo nguồn nhân lực, nâng cao chất lượng nguồn nhân lực, tạo công việc làm cho người học sau khi tốt nghiệp. Chính vì vậy nhóm ngành khoa học Trái đất - Mỏ - Môi trường cần thay đổi cải cách chương trình đào tạo theo xu hướng cải cách của thế giới, mở các ngành mới theo xu hướng phát triển khoa học kỹ thuật phục vụ cho đời sống của con người trong tương lai.

\section{Xu thế cải cách chương trình đào tạo tại các nước trên thế giới \\ 2.1. Xu thế cải cách chương trình đào tạo tại $M \tilde{y}$}

Tại Mỹ có hơn 3.000 trường đại học thực hiện giáo dục ở các cấp chuyên nghiệp thực hành, đại học, thạc sĩ và tiến sĩ. Các trường được phân thành các trường đại học nghiên cứu (như PHD và các trường có thứ hạng của $\mathrm{Mỹ}$ ), các trường đại học và thạc sĩ (xếp hạng theo khu vực hoặc xếp hạng theo khoa học). Theo thể chế đào tạo phân thành các trường đại học tư (Harvard, Yale, Princeton, Stanford, MIT, v.v.), các trường đại học công (Berkeley, California, Michigan, Virginia, Michigan, Columbia, v.v.) và các trường chuyên nghiệp thực hành, ngoài ra còn hệ thống giáo dục trọn gói các cấp học từ nhà trẻ đến tiến sĩ, loại hình này có yêu cầu khá cao [2-4].

Xu thế cải cách chương trình đào tạo tại Mỹ theo hướng [1,5]:

- Đẩy mạnh công tác giáo dục đạo đức và giáo dục giá trị lối sống, kỹ năng sống;

- Chính phủ chủ động hướng dẫn, các tổ chức và xã hội tích cực tham gia;

- Phát triển hài hòa thống nhất và đa dạng về cấu trúc chương trình đào tạo và đánh giá chương trình đào tạo.

- Đẩy mạnh theo hướng nghiên cứu khoa học kỹ thuật liên hệ với các ngành xã hội nhân văn.

- Kết hợp cải cách chương trình đào tạo trước đây để tiến hành cải cách toàn diện.

\subsection{Xu thế cải cách chương trình đào tạo tại Đúc}

Tại Đức gồm hai loại trường, thứ nhất là loại trường đại học tổng hợp loại này gồm 114 trường với nhiều chuyên ngành đào tạo, trong đó chú trọng giảng dạy kết hợp với nghiên cứu gồm các trường đại học tự nhiên, đại học sư phạm, đại học tổng hợp, các trường đều có các hệ đào tạo đại học, thạc sĩ và tiến sĩ. Thứ hai là loại trường đại học kỹ thuật ứng dụng gồm 152 trường, thường đào tạo các ngành về công trình, kỹ thuật, nông nghiệp, nghệ thuật, thiết kế, kinh tế, tài chính và công thương v.v. để đào tạo nhân tài mang tính ứng dụng.

Những năm gần đây chính phủ Đức đã phát động chương trình đại học tài năng và chính phủ đã chi những khoản tiền khổng lồ để hỗ trợ xây dựng và phát triển các trường đại học cao cấp, khuyến khích nghiên cứu khoa học phát triển công nghệ.

Đặc điểm của các trường đại học của Đức được kết hợp rất chặt chẽ với các doanh nghiệp. Sinh viên học tập tại trường khoảng 3 đến 4 năm còn thực tập trong một Công ty, cơ sở sản xuất hoặc ở nước ngoài với thời gian khoảng 6 tháng. Luận văn tốt nghiệp tập trung vào ứng dụng và thường được yêu cầu phải hoàn thành tại doanh nghiệp [2-4].

Xu thế cải cách chương trình đào tạo tại Đức theo hướng [1,7]:

- Chương trình đào tạo theo hướng đa dạng hóa môi trường học tập, các tổ chức giáo dục mở rộng sang các lĩnh đời sống thường ngày;

- Chương trình đào tạo tập trung vào khả năng tiếp thu kiến thức trên giảng đường và thực hành tại các doanh nghiệp; 
- Chương trình đào tạo theo hướng khích lệ, khuyến khích học tập và phát huy năng lực hợp tác;

- Đánh giá lại vai trò của giáo viên và học sinh.

- Phát triển đào tạo các khả năng sở trường của học sinh;

\subsection{Xu thế cải cách chuơng trình đào tạo tại Úc}

Tại Úc số lượng các trường đại học không nhiều nhưng chất lượng khá cao, tổng cộng có khoảng 40 trường đại học, trong đó có 37 trường công.

Các cấp học gồm giáo dục đại học hoặc dạy nghề (TAFE), Associate's Degree, đại học (bao gồm cả bằng học sĩ danh dự), thạc sĩ và tiến sĩ. Nước Úc có dân số ít và có thể coi là một nước thực hiện công nghiệp hóa giáo dục, thu hút nhiều sinh viên tại các nước khác nhau trên thế giới đến theo học. Số lượng sinh viên quốc tế lớn và thu học phí cao hơn nhiều so với sinh viên trong nước. Năm 2000 chính phủ Úc đã thực hiện chương trình kế hoạch "Backing Australia's Ability". Mỗi năm quỹ hỗ trợ giáo dục rất lớn và được phân bổ để hỗ trợ giáo dục đại học, hỗ trợ nghiên cứu khoa học và tài trợ cấp học bổng cho các sinh viên trong và ngoài nước [2-4].

$\mathrm{Xu}$ thế cải cách chương trình đào tạo tại Úc theo hướng $[1,6]$ :

- Phát triển nội dung chương trình đào tạo mang tính đa dạng hóa và mở rộng các chương trình đào tạo theo các ngành mang tính thời đại;

- Dân chủ hóa chế độ quản lý chương trình đào tạo, phân quyền quản lý chương trình đào tạo;

- Xây dựng mô hình mục tiêu chương trình để đào tạo nhân tài có tính chuyên nghiệp cao;

- Phương thức tổ chức chương trình đào tạo kết hợp tính phổ biến với chọn lọc.

\subsection{Xu thế cải cách chưong trình đào tạo tại Pháp}

Giáo dục Pháp được phân thành các trường đại học tổng hợp công và các viện chuyên nghiệp ưu tú (như học viện công trình, viện kinh doanh, viện kiến trúc, v.v.). Chất lượng của các trường đại học công thường là trung bình, tại các trường này cơ bản đều dùng tiếng Pháp để học tập. Còn các viện chuyên nghiệp thì chất lượng đào tạo tốt hơn, toàn bộ quá trình đào tạo sử dụng ngôn ngữ tiếng anh. Cấp bậc học cũng được chia thành các hệ thống đại học, thạc sĩ và tiến sĩ. Ngoài ra còn có giáo dục chuyên ngành, chủ yếu là đào tạo các nhân tài về mảng nghệ thuật, thiết kế, thời trang và du lịch.

Các trường đại học Pháp được chia thành trường công và tư. Trường công không phải đóng học phí còn trường tư phải đóng học phí, về chất lượng đào tạo có sự khác biệt giữa các trường. Hiện có 87 trường đại học tổng hợp công, 3 trường đại học tổng hợp tư, hơn 400 viện đào tạo về công trình, hơn 200 viện công lập, tư lập đào tạo về nghệ thuật và gần 1000 viện đào tạo kinh doanh [2-4].

Xu thế cải cách chương trình đào tạo tại Pháp theo hướng $[1,8]$ :

- Nội dung chương trình đào tạo phát triển theo hướng chú trọng đào tạo mang tính thực dụng và thiết thực với cuộc sống;

- Chương trình đào tạo coi trọng kiến thức cơ sở, kiến thức nền tảng;

- Chương trình đào tạo kết hợp các loại hình giáo dục với nhau;

- Chương trình đào tạo phân theo khu vực đào tạo, đào tạo theo ngôn ngữ tiếng Pháp và tiếng Anh

- Cá nhân hóa giáo dục đáp ứng nhu cầu học tập của học sinh;

\subsection{Xu thế cải cách chwơng trình đào tạo} tại Anh

Tại Anh có nền giáo dục cũng tương đồng với Mỹ, phân thành các cấp đào tạo chuyên nghiệp thực hành, đại học, thạc sĩ và tiến sĩ. Nhưng trong đào tạo đại học và thạc sĩ đều có dạng đào tạo loại hình "taught" và loại hình "research" với thành tích cao có thể nhận học vị "honorable Bachelor" và "honorable Master". Loại honorable Bachelor có thể xin học trực tiếp lên tiến sĩ.

Tại Anh có hơn 200 trường đại học, thường 
được chia thành các trường đại học và học viện. Trường đại học ngoài có một trường tư còn tất cả đều là trường công. Các trường có quyền tự chủ rất lớn, có thể tự cấp bằng học vị, nhưng phải được đánh giá chất lượng khách quan bên ngoài trường. Một số trường nổi tiếng nhất được kiểm định chất lượng bởi tổ chức QAA [2-4].

Xu thế cải cách chương trình đào tạo tại Anh theo hướng $[1,5]$ :

- Cải cách theo hướng tìm điểm cân bằng giữa “chất lượng” và "bình đẳng" trong chương trình đào tạo.

- Chú trọng giáo dục chức vụ nghề nghiệp và giáo dục phổ thông.

- Chương trình đào tạo tăng cường tính linh hoạt và độ sâu rộng.

- Chương trình đào tạo hướng đến mọi người đều nắm vững được các kỹ năng chính trong nghề nghiệp của mình.

- Chương trình đào tạo theo hướng nâng cao mở rộng học theo hình thức cấp chứng chỉ sau mỗi khóa đào tạo.

\subsection{Xu thế cải cách chuơng trình đào tạo tại Hàn Quốc}

Các trường đại học Hàn Quốc được chia thành các trường cao đẳng, đại học, đại học tổng hợp, và viện nghiên cứu. Trường cao đẳng đào tạo 2-3 năm và là một phần quan trọng của giáo dục nghề nghiệp của Hàn Quốc, đại học đào tạo 4 năm.

Tại Hàn Quốc có khoảng gần 500 các trường đại học và cao đẳng, các trường đại học luôn có sự đa dạng về ngành nghề đào tạo và hệ đào tạo đa dạng từ cao đẳng, cử nhân, kỹ sư tới thạc sĩ, tiến sĩ. Với chương trình giảng dạy kết hợp lí thuyết với thực tiễn, sinh viên đại học được chỉ định phục vụ trong một trường với một thời gian nhất định sau khi tốt nghiệp.

Xu thế cải cách chương trình đào tạo tại Hàn Quốc theo hướng $[1,11]$ :

- Xây dựng chương trình hệ thống đánh giá chương trình giáo dục và tăng cường quản lý chất lượng giáo dục;

- Xây dựng chương trình đào tạo với các trình độ khác nhau;

- Xây dựng chương trình đào tạo chung theo giai đoạn, theo niên chế chung cho quốc gia;

- Quy mô đào tạo từ yêu cầu đơn lẻ sang yêu cầu phức hợp và đa cấp độ đào tạo.

\subsection{Xu thế cải cách chương trình đào tạo tại Nhật Bản}

Tại Nhật Bản có 765 trường đại học với thời gian niên chế đào tạo 4 năm, trong đó có 86 trường quốc lập (hầu như không thu bất kể phí nào, chương trình học thường mang tính học thuật cao), 90 trường công (thu một nửa phí học đối với học sinh trong tỉnh, ngoài tỉnh thu 100\% học phí, chương trình học mang tính học thuật, một số trường có thêm các ngành học mang tính ứng dụng), 589 trường tư (thu 100\% học phí và khác phí khác, khoảng 10 trường tư top đầu có môi trường học mở, mang tính quốc tế cao, chương trình học mang tính ứng dụng, các trường trung bình hoặc mức dưới ít được người Nhật Bản biết đến, thường nhận nhiều du học sinh châu Á) [17]. Dựa vào loại hình phân thành đại học tổng hợp, đại học đa ngành, đại học đơn ngành, đại học nữ giới, học sinh có thành tích học tập tốt đều có thể xin được học bổng cấp tỉnh của Nhật Bản đủ để học tập và sinh hoạt trong suốt quá trình học tập.

Đại học khoa học thực nghiệm đều có người dẫn đầu trong khoa học, thường mỗi ngành chỉ có 1 giáo sư và vài phó giáo sư, khi giáo sư về hưu thì từ những phó giáo sư chọn 1 người để thay thế. Các giáo sư có thể xin tài trợ nghiên cứu khoa học và tự mình có thể tự quyết định chi tiêu cho nghiên cứu trong đó bao gồm quyền sử dụng kinh phí mua các thiết bị.

Xu thế cải cách chương trình đào tạo tại Nhật Bản theo hướng $[1,9,10]$ :

- Chương trình tập trung vào việc đào tạo khả năng học tập độc lập và tư duy độc lập.

- Chương trình tập trung vào nền giáo dục học đường, giảng dạy trên lớp.

- Xây dựng phát triển chương trình đào tạo, tổ chức đào tạo và thực hiện đào tạo mang tính linh hoạt. 
- Chương trình chú trọng đến thiết lập chương trình đào tạo mang tính cá nhân hóa, đa dạng hóa và tích hợp hóa.

\subsection{Xu thế cải cách chương trình đào tạo tại Trung Quốc}

Tại Trung Quốc đến năm 2009 tổng cộng có khoảng 1079 Trường Đại học và trên đại học, trong đó có 710 trường công (Bộ giáo dục trực tiếp quản lý 73 trường). Đối với chương trình đại học, có các khoá học nghề cũng như các khoá học cấp bằng đại học, sau đại học, và tiến sĩ. Sinh viên theo học cử nhân, kỹ sư sẽ học trong vòng 4-5 năm, chương trình thạc sỹ kéo dài 2-3 năm và tiến sỹ trong 3 năm [2-,4].

$\mathrm{Xu}$ thế cải cách chương trình đào tạo tại Trung Quốc theo hướng [1]:

- Xây dựng chương trình đào tạo mang tính tổng hợp;

- Xây dựng chương trình đào tạo mang tính định hướng cho con người.

- Xây dựng chương trình kết hợp chương trình đào tạo trong và ngoài nước.

- Xây dựng chương trình đào tạo với mục đích đào tạo thông minh.

- Thiết lập một hệ thống đánh giá đa chiều trong cải cách chương trình đào tạo.

Nhận xét: Như vậy ta có thể thấy rằng hiện nay $\mathrm{xu}$ thế chung cải cách chương trình đào tạo trên thế giới theo các hướng sau:

- Tích hợp chương trình đào tạo mang tính khoa học với xã hội nhân văn;

- Mở rộng xác định, lựa chọn các mục tiêu cho chương trình đào tạo;

- Xây dựng chương trình đào tạo mang tính toàn cầu hóa;

- Chú trọng nâng cao chương trình đào tạo lý thuyết cơ bản;

- Kết hợp mang tính thống nhất và linh hoạt trong chương trình đào tạo;

- Tăng cường giáo dục về đạo đức lối sống cho học sinh sinh viên;

- Chú trọng việc đào tạo tính cách cho học sinh sinh viên.

- Hướng đến nền giáo dục phát triển tôn trọng sinh mạng trong cuộc sống của con người.

- Mở rộng phạm vi cải cách chương trình đào tạo, đi sâu vào nội dung khoa học;

\section{Thách thức và cơ hội nguồn nhân lực} lĩnh vực Trái đất - Mỏ - Môi trường trong bối cảnh toàn cầu hóa giáo dục

3.1. Thách thức đào tạo nguồn nhân lục lĩnh vục Trái đất - Mỏ - Môi trường

Cuộc chạy đua về thị phần giáo dục quốc tế của các ngành khoa hoc mới đã tác động sấu đến công tác đào tạo nguồn nhân lực ngành khoa học truyền thống trong đó có các ngành Trái đất - Mỏ - Môi trường. Người học, những nhà khoa học trẻ theo xu hướng tập trung học và nghiên cứu các ngành khoa học mới có triển vọng, công việc nhẹ nhàng, thu nhập cao, điều kiện môi trường làm việc ổn định, ra trường có nhiều sự lựa chọn về vị trí việc làm.

- Tài liệu giảng dạy, sách, bài giảng chưa chú trọng thay đổi nội dung và phương pháp giảng dạy, chưa bám sát với điều kiện thực tế, công tác thực hành tại hiện trường chưa được chú trọng, phương pháp nghiên cứu học tập chưa theo kịp với thời đại công nghệ 4.0;

- Các thiết bị giảng dạy, thực hành cơ sở vật chất phục vụ cho công tác học tập và nghiên cứu còn lạc hậu, nhiều thiết bị cũ từ những năm 70 vẫn còn được sử dụng trong đào tạo và nghiên cứu khoa học;

- Các chuyên ngành, phạm vi nghiên cứu trong các ngành khoa học Trái đất - Mỏ - Môi trường không còn sức thu hút được đối với người học, mặt khác chưa kịp thời phát triển đào tạo về lĩnh vực nguồn năng lượng mới, nguồn năng lượng sạch, nguồn năng lượng không làm biến đổi khí hậu môi trường.

- Công tác đào tạo, lựa chọn đội ngũ đào tạo, nghiên cứu kế cận cho ngành khoa học Trái đất - Mỏ - Môi trường còn nhiều bất cập, mặt khác những nhà nghiên cứu có tâm huyết, chuyên môn tốt ngày một tuổi cao khó đáp ứng được các điều kiện nghiên cứu tại hiện trường, tại điều kiện thời tiết khó khăn khắc nghiệt của ngành;

- Điều kiện làm việc và nghiên cứu trong lĩnh 
vực ngành khoa học Trái đất - Mỏ - Môi trường khó khăn vất vả, nhiều công việc nặng nhọc, nguy hiểm, độc hại, tiềm ẩn nhiều rủi ro;

- Mức thu nhập cho cán bộ đào tạo và nghiên cứu ngành khoa học Trái đất - Mỏ - Môi trường so với các ngành khoa học trẻ khác còn hạn chế;

- Tài nguyên khoáng sản rắn dần đã cạn kiệt và có sản lượng khai thác có xu hướng giảm trong tương lai;

\subsection{Co hội đào tạo nguồn nhân lục lĩnh vụcc}

\section{khoa hoc Trái đất - Mỏ - Môi trường}

Cũng như các ngành khoa học trẻ khác trong bối cảnh hội nhập toàn cầu, trong bối cảnh kinh tế toàn cầu, trong bối cảnh phát triển các nguồn năng lượng sạch, bảo vệ môi trường, tìm kiếm nguồn tài nguyên mới thay thế cho nguồn tài nguyên khoáng sản truyền thống thì cơ hội đào tạo nguồn nhân lực trong lĩnh vực khoa học Trái đất - Mỏ - Môi trường cũng đã mở ra với nhiều kỳ vọng như:

- Toàn cầu hóa giúp cho việc trao đổi đào tạo, học hỏi kinh nghiệm, tập huấn nghiệp vụ nâng cao trình độ chuyên môn giữa các quốc gia trên thế giới trở lên đơn giản và thuận tiện hơn, bằng cách đào tạo trực tuyến, tại chỗ, ứng dụng công nghệ thông tin vào giảng dạy đào tạo;

- Xu thế thay thế nguồn năng lượng truyền thống bằng các nguồn năng lượng tái tạo như năng lượng mặt trời, năng lượng gió, năng lượng sóng biển dẫn đến thiếu hụt nguồn nhân lực trong lĩnh vực này bởi đây là một ngành rất mới không chỉ đối với nước ta mà cả các nước trên thế giới;

- Sự phát triển ứng dụng, sử dụng các vật liệu tái chế từ rác thải xây dựng, rác thải sinh hoạt, phế thải nhiệt điện;

- Ngày càng có nhiều các dự án nghiên cứu về biến đổi khí hậu môi trường trong và ngoài nước, nguồn nhân lực làm việc và nghiên cứu trong lĩnh vực này còn hạn chế, chưa đáp ứng được nhu cầu công việc và công tác nghiên cứu;

- Công tác bảo vệ môi trường ngày càng được các quốc gia trên toàn thế giới quan tâm, ngày càng có nhiều các dự án về bảo vệ môi trường, xử lý môi trường trên khắp thế giới;

- Trong và ngoài nước đang có nhiều các dự án xây dựng với quy mô lớn tạo ra nhiều việc làm thu hút được nhiều lao động chuyên môn trong lĩnh vực đào tạo ngành khoa học Trái đất Mỏ - Môi trường;

- Chính phủ các nước đều tăng cường đầu tư vào các dự án đổi mới khoa học và công nghệ, tăng về số lượng và hỗ trợ của các dự án nghiên cứu khoa học ở nhiều cấp khác nhau trong lĩnh vực khoa học Trái đất - Mỏ - Môi trường;

- Chính phủ các nước đang có nhiều dự án mở rộng tìm kiếm nguồn tài nguyên biển;

- Chính phủ các nước luôn quan tâm đến giáo dục, đặc biệt trong bối cảnh toàn cầu hóa.

IV. Giải pháp nâng cao nguồn nhân lực trong lĩnh vực đào tạo ngành khoa học Trái đất Mỏ Môi trường

Nhân lực là yếu tố quyết định đến thành công và tiến bộ của mỗi ngành đào tạo, trong đó trình độ phát triển nguồn nhân lực là thước đo chủ yếu đánh giá mức độ tiến bộ của ngành và phát triển bền vững. Để phát triển nguồn nhân lực lĩnh vực khoa học Trái đất - Mỏ - Môi trường cần phải xây dựng tầm nhìn chiến lược phát triển tổng thể và dài hạn của ngành. Đồng thời, trong mỗi giai đoạn nhất định, cần xây dựng những chương trình hành động với mục tiêu, định hướng cụ thể, trong đó phân tích, đánh giá thời cơ, thách thức, những khó khăn, hạn chế và nguyên nhân... để đề ra mục tiêu và giải pháp cho từng giai đoạn phù hợp với bối cảnh kinh tế - xã hội trong nước và quốc tế.

Trong bối cảnh toàn cầu hóa giáo dục hiện nay công tác đào tạo nguồn nhân lực chất lượng cao trong lĩnh vực khoa học Trái đất - Mỏ - Môi trường cần phải thực hiện các nhóm giải pháp sau:

Nhóm giải pháp về nâng cao trình độ đội ngũ đào tạo, nghiên cứu:

- Công tác nâng cao trình độ chuyên môn cho đội ngũ đào tạo, nghiên cứu khoa học: Tăng cường bồi dưỡng thường xuyên, tập huấn ngắn hạn nâng cao trình độ chuyên môn cho đội ngũ 
đào tạo, nghiên cứu khoa học bằng các khóa học dài hạn và ngắn hạn tại các nước phát triển trên thế giới;

- Nâng cao trình độ ngoại ngữ cho cán bộ đào tạo, nghiên cứu bằng cách tổ chức các lớp học ngoài giờ làm việc, tăng cường hợp tác giao lưu với các đơn vị nước ngoài;

- Thường kỳ tổ chức các buổi hội thảo, báo cáo học thuật, hội nghị khoa học liên quan đế các vấn đề thời sự, các vấn đề bất cập chưa có hướng giải quyết tại các cơ sở sản xuất trong lĩnh vực khoa học Trái đất - Mỏ - Môi trường;

- Xây dựng các chương trình, đề án, đề tài nghiên cứu cấp quốc gia, tỉnh, thành phố, cấp bộ...vv để thực hiện;

- Xây dựng các dự án phối hợp nghiên cứu với các cơ sở đào tạo nghiên cứu nước ngoài;

- Xin các nguồn tài trợ phục vụ nghiên cứu, nâng cao trình độ đội ngũ đào tạo, nghiên cứu.

Nhóm giải pháp về cải cách chương trình đào tạo:

- Xây dựng các chương trình đào tạo theo hướng phát triển các ngành mới về môi trường, năng lượng mặt trời, năng lượng gió, năng lượng sóng biển, năng lượng sạch, tin học khoa học Trái đất - Mỏ - Môi trường;

- Hoàn thiện các chương trình đào tạo theo hướng mở, hội nhập, phân cấp đào tạo. Đổi mới nội dung, chương trình, tài liệu đào tạo theo hướng phát huy tư duy sáng tạo, năng lực tự học, tự nghiên cứu, tăng thời gian thực hành;

- Đổi mới phương pháp dạy và học theo hướng học đi đôi với thực hành tại hiện trường, học tại các cơ sở sản xuất;

- Mỗi chương trình đào tạo cần có đánh giá kiểm định chất lượng đào tạo. Cải cách mục tiêu, nội dung, hình thức kiểm tra, thi và đánh giá kết quả đào tạo;

- Cải cách chương trình đào tạo theo xu hướng đào tạo theo nhu cầu ngoài thực tế, kết hợp với các cơ sở sản xuất đào tạo theo yêu cầu, phối hợp, liên kết đào tạo với các nước phát triển trên thế giới;

- Điều chỉnh các chương trình đào tạo và mô hình đào tạo phù hợp với tiêu chuẩn quốc tế;

- Xây dựng chương trình theo hướng đẩy mạnh giáo dục đạo đức lối sống của sinh viên.

Nhóm giải pháp về đầu tư trang thiết bị phục vụ cho đào tạo và nghiên cứu:

- Tăng cường đầu tư cơ sở vật chất, trang thiết bị đào tạo nguồn nhân lực trong lĩnh vực khoa học Trái đất - Mỏ - Môi trường;

- Tận dụng tối đa cơ sở vật chất hiện có của các cơ sở đào tạo, nghiên cứu khoa học;

- Xây dựng kế hoạch trang bị thêm thiết bị tối thiểu cho những ngành học, tăng cường xã hội hoá, tranh thủ sự hỗ trợ về mọi mặt của các đơn vị sản xuất và cộng đồng xã hội để đầu tư mua sắm các trang thiết bị.

Nhóm giải pháp tăng cường kết hợp với các cơ sở nghiên cứu, doanh nghiệp:

- Vận động các cơ sở nghiên cứu khoa học, các doanh nghiệp tích cực hỗ trợ các sinh viên tiếp cận với môi trường làm việc thực tế thông qua các đợt thực tập và đào tạo các kỹ năng làm việc tại các doanh nghiệp;

- Tăng cường hợp tác nghiên cứu, phát triển và triển khai các công nghệ mới cũng như chia sẻ các kinh nghiệm và chuyên môn theo nhu cầu thực tế giữa cơ cở đào tạo, cơ quan nghiên cứu với doanh nghiệp;

- Hợp tác với các doanh nghiệm trong công tác đào tạo nguồn nhân lực bằng cách các doanh nghiệp sẽ đặt hàng các yêu cầu về nội dung nhà trường cần đào tạo để đáp ứng nhu cầu của doanh nghiệp, doanh nghiệp đóng vai trò phản biện trong việc xây dựng chương trình đào tạo của nhà trường;

- Các doanh nghiệp, các cơ sở nghiên cứu tạo môi trường thuận lợi cho sinh viên đến tham quan, thực tập; tuyển dụng sinh viên sau khi ra trường. Tham gia ngày hội việc làm của sinh viên do trường tổ chức. Cử các doanh nhân có trình độ và kinh nghiệm thực tiễn đến báo cáo chuyên đề hoặc tham gia giảng dạy, nghiên cứu khoa học tại trường. Đặt hàng các nghiên cứu khoa học phục vụ giải quyết các vấn đề của doanh nghiệp; 
- Các doanh nghiệp cần có quan hệ hợp tác giữa trường đại học trên nền tảng bình đẳng cùng có lợi. Trong việc hợp tác này, trường đại học sẽ: cung cấp nguồn nhân lực đáp ứng yêu cầu của doanh nghiệp; sáng tạo ra tri thức mới và chuyển giao công nghệ cho doanh nghiệp; cử giảng viên đến doanh nghiệp làm công tác tư vấn và phối hợp với doanh nghiệp để cùng giải quyết các vấn đề của doanh nghiệp; cử sinh viên đến tham quan, thực tập tại doanh nghiệp; thiết lập bộ phận chuyên trách về liên kết với doanh nghiệp; hình thành các trung tâm nghiên cứu phục vụ cho doanh nghiệp.

Nhóm giải pháp chủ động hội nhập quốc tế

- Xây dựng, hoàn thiện hệ thống văn bản pháp luật về phối hợp đào tạo phát triển nguồn nhân lực phù hợp với Việt Nam nhưng không trái với thông lệ và luật pháp quốc tế;

- Cùng với các cơ sở đào tạo nước ngoài thiết lập khung trình độ ngành khoa học Trái đất - Mỏ - Môi trường. Xây dựng lộ trình nội dung, chương trình và phương pháp đào tạo;

- Tham gia kiểm định quốc tế chương trình đào tạo. Thực hiện đánh giá và quản lý chất lượng theo tiêu chuẩn quốc tế, liên kết, trao đổi về giáo dục và đào tạo đại học, sau đại học và các đề tài, dự án nghiên cứu khoa học, công nghệ giữa các cơ sở giáo dục đại học Việt Nam và thế giới;

- Tạo môi trường và điều kiện thuận lợi để thu hút các nhà giáo, nhà khoa học có tài năng và kinh nghiệm của nước ngoài, người Việt Nam ở nước ngoài tham gia vào quá trình đào tạo nhân lực đại học và nghiên cứu khoa học, công nghệ.

Nhóm giải pháp giáo dục hướng nghiệp, tổ chức hướng nghiệp cho người học:

- Hướng nghiệp trước khi vào học: Để đảm bảo sinh viên sau khi theo học ngành khoa học Trái đất - Mỏ - Môi trường tìm được việc làm ổn định, yêu nghề cần có sự tư vấn hướng nghiệp cho học sinh thông sở thích, năng lực, hoàn cảnh gia đình, nhu cầu xã hội từ đó có thể tổ chức dạy nghề phổ thông cho học sinh, cho học sinh thực hiện các công việc đơn giản liên quan đến ngành khoa học Trái đất -Mỏ - Môi trường. Ngoài ra cũng cần cập nhật thông tin thị trường lao động và xác định những yêu cầu kỹ năng công việc trong tương lai. Cung cấp những thông tin này cho các bậc phụ huynh và các em học sinh sẽ giúp ích cho sự lựa chọn các ngành nghề rõ ràng và chính xác hơn.

- Hướng nghiệp sau khi vào học: Ngoài việc học kiến thức và kỹ năng chuyên môn về chuyên ngành khoa học Trái đất - Mỏ - Môi trường sinh viên cần được tăng cường thêm năng lực về một số mặt: ngoại ngữ, kỹ năng mềm, phong cách làm việc chuyên nghiệp, văn, thể, mỹ...vv. Các năng lực này sẽ được rèn luyện thông qua các hoạt động ngoại khóa, các hoạt động ở các câu lạc bộ, các hoạt động tham gia nghiên cứu, tham dự hội thảo, báo cáo học thuật.

- Ngoài các nhóm giải pháp trên cần phải Nhà nước cần có thêm các ưu đãi, chính sách ưu tiên, nâng cao nguồn thu nhập và tạo điều kiện hơn nữa cho các cán bộ làm công tác đào tạo nguồn nhân lực trong linh vực khoa học Trái đất - Mỏ - Môi trường nói riêng và cho các cán bộ làm công tác đào tạo nguồn nhân lực nói chung.

\section{Kết luận}

Toàn cầu hóa vừa là mục tiêu nhưng cũng là động lực và biện pháp để các nước trên thế giới có thể thay đổi chương trình đào tạo, cải cách giáo dục, với các ngành đào tạo chưa cải cách kịp theo xu hướng toàn cầu hóa sẽ gặp phải nhiều bất cập và khó khăn trong đào tạo nguồn nhân lực. Đứng trước những thách thức và cơ hội toàn cầu hóa các ngành khoa học Trái đất - Mỏ - Môi trường cũng cần phải tiếp tục đẩy mạnh công tác cải cách chương trình đào tạo để bắt kịp với xu thế đào tạo nguồn nhân lực hội nhập quốc tế.

Bài viết đã tổng quan về xu thế cải cách chương trình đào tạo trong bối cảnh toàn cầu hóa, nếu ra các thách thức cơ hội và đưa ra các nhóm giải pháp cải cách chương trình đào tạo các ngành ngành khoa học Trái đất - Mỏ - Môi trường nhằm nâng cao trình độ cho nguồn nhân lực và tạo việc làm bền vững. Kính đề nghị các cơ sở đào tạo các chuyên ngành khoa học Trái 


\section{BÀI BÁO KHOA HỌC}

đất - Mỏ - Môi trường tiếp tục từng bước cải

được nguồn nhân lực đáp ứng được các công cách, đổi mới chương trình đào tạo để nâng cao

việc trong bối cảnh toàn cầu hóa.

\section{Tài liệu tham khảo}

1. Jiang, Z., (2017), Đặc trung cải cách chương trình đào tạo trên thế giới. Chương trình hóa học và lý luận dạy học).

2. Hua, H.W., (2014), Quốc tế hóa giáo dục co hội thách thức của giáo dục đại học TQ. Truờng Đại học Tây An, Phòng hợp tác Quốc tế.

3. Hui, M.W., (2006), Cải cách giáo duc trong quá trình quốc tế hóa. Nguồn: Nghiên cứu so sánh giáo dục.

4. Ling, L.L., (2015), Thảo luận về xu thế phát triển chuơng trình đào tạo và giảng dạy quốc tế thế kỷ 21 .

5. Ming, F.Y., (2006), Hiện trạng và xu thế cải cách chuơng trình dạy học của Mỹ và Anh. Nguồn: Người giáo dục.

6. Xia, W., (2006), Về đặc điểm, khó khăn và vấn đề cách cách churong trình đào tạo đương đại của Úc. Nguồn: Nghiên cứu giáo dục nước ngoài.

7. Feng, Z.X., (2005), Đánh giá cái cách chưong trình giảng dạy khoa học tổng hợp của Đức. Nguồn: Thông tin giáo dục thế giới.

8. Linh, W., (2001), Nắm vũ̃ng nền tảng chung của năng lục tri thức - xu hướng cải cách chuoong trình đào tạo của Pháp. Nguồn: Phát triển giáo dục toàn cầu.

9. Xia, G.W., (2001), Đánh giá cải cách chuơng trình giáo dục của Nhật Bản hiện nay. Nguồn: Nghiên cứu so sánh giáo dục.

10. Feng, X.G., (2006), Văn hóa Nhật Bản và cải cách chương trình giáo dục đương đại. Nguồn: Nghiên cứu vấn đề Nhật Bản.

11. Lin, S.Q., (2001), Đối mặt với cải cách chưong trình giáo dục Hàn Quốc thế kỷ 21- Đánh giá cải cách chuoơng trình giáo dục lần thứ 7 Hàn Quốc. Nguồn: Nghiên cứu giáo dục nước ngoài.

12. Tran, T.T., (2012), Internationalisation of higher education in Vietnam: Opportunities and challengs, in Internationalisation of higher education: North-South perspectives, International School, Vietnam National University, Hanoi: Hanoi.

13. Huang, F., (2007), Internationalization of higher education in the developing and emerging countries: A focus on transnational higher education in Asia. Journal of Studies in International Education, 11 (3-4), 421-432.

14. Wang, Y., 2008. Internationalization in Higher Education in China: A Practitioner's Reflection. Higher Education Policy, 505-517.

15. Hiếu Nguyễn (2019), Quốc tế hóa - động lục đổi mói đào tạo giáo dục đại học.

https://www.moit.gov.vn/tin-chi-tiet/-/chi-tiet/quoc-te-hoa-\%C4\%91ong-luc-\%C4\%91oi-moi$\%$ C4\%91ao-tao-giao-duc-\%C4\%91ai-hoc-13184-402.html

16. Nguyễn Thị Đào. Toàn cầu hoá. Tạp chí Thu viện Việt Nam. Tạp chí Thư viện Việt Nam. http://nlv.gov.vn/nghiep-vu-thu-vien/toan-cau-hoa-co-hoi-va-thach-thuc-doi-voi-nganh-thong-tin$\% \mathrm{E} 2 \% 80 \% 93$-thu-vien-viet-nam.html

17. So sánh đại học quốc lập, công lập, tu lập tại Nhật Bản (2017). https://isenpai.jp/so-sanh-daihoc-quoc-lap-cong-lap-tu-lap-tai-nhat/. 


\title{
TRENDS REFORM OF TRAINING PROGRAMS IN COUNTRIES ON THE WORLD - CHALLENGES AND OPPORTUNITIES OF EARTH - MINING - ENVIRONMENT FOR HUMAN RESOURCES
}

\author{
Dao Viet Doan', Do Ngoc Anh', Dang Trung Thanh', \\ Tran Tuan Minh ${ }^{1}$, Nguyen Van Manh ${ }^{1}$ \\ ${ }^{1}$ Hanoi University of Mining and Geology
}

\begin{abstract}
This paper provides an overview of globalization education, importance of curriculum reform and introduction a curriculum reform on the world. Based on the analysis of challenges, difficulties, opportunities for enhancement of Earth - Mining - Environment for human resources globalization and reforming training programs in the world. The authors have proposed a number of necessary solutions to improve the quality of human resource training for current requirements Earth - Mining - Environment sciences, including: Improving qualifications scientific research training team; Training curriculum reform; Investing in material facilities and equipment service of training and scientific research; Cooperation with research institutions and enterprises; Proactive international integration; Vocational education and vocational organization for learners.
\end{abstract}

Keywords: training programs reforms, Improving human resources, Earth - Mining - Environment science 